\title{
Hemorheological studies of chosen clinical cases
}

\author{
Anna Marcinkowska-Gapińska, Piotr Kowal \\ Rheological Lab, Department of Neurology, Poznan University of Medical Sciences, Poland
}

\begin{abstract}
Rheology - the study of the flow of matter and accompanying phenomena of real bodies deformation - in relation to blood - hemorheology. Blood viscosity - the main rheological parameter - has been studied in many research centers and among many different group of patients. The main disorders related to the hemorheological properties are: coronary insufficiency, vascular congestion, myocardial infarction, cerebral circulation disorder, Reynaud disease, ischemic limbs, diabetes, anemia, tumors. The following parameters are the main blood viscosity determinants: plasma viscosity, hematocrit, red cell deformability and erythrocytes aggregation. In hemorheological studies we used mathematical rheological models. The measurements of blood and plasma viscosity are performed by means of oscillating-rotary rheometers in order to determine the dependence of blood viscosity on the shear rate and the two components of the complex blood viscosity. Determination of blood cells aggregability and deformability is performed directly by means of aggregometers and appropiate filters and indirectly using rheological techniques with advanced mathematical models of blood viscoelasticity. Blood and plasma viscosity are subject to autoregulation mechanisms of the body. Recognition of those mechanisms may help in assessment of some diseases risk: ischemic stroke or myocardial infarction. In many cases rheological measurements may reveal the most recent phases of diseases and disorderses which enables early therapy with specimens improving the blood fluidity. For this reason rheological measurements should be applied in diagnostics and therapy. Mutual relations between the main factors determining the blood viscosity and their effect on blood flow are the main subject of current report.
\end{abstract}

Keywords: hemorheology, blood viscosity, abnormal aggregability, abnormal deformation.

\section{Introduction}

Blood is a systemic liquid of clearly non-Newtonian character and of distinctly pronounced viscoelastic properties. Blood flow in the circulatory system depends on the physical and physicochemical properties of blood as well as on many phenomena resulting from the structure and properties of the circulatory system.

Blood is a suspension of morphotic blood elements (erythrocytes, leukocytes, blood platelets) in plasma and its viscosity is dependent on the shear rate. Analysis of the physico-chemical properties of blood is related to hemorheology - a field of science focusing on the phenomena related to the flow of blood. Blood viscosity is determined by the following parameters: plasma viscosity, hematocrit, red cell deform- ability and aggregability [1, 2]. Shear rate dependence of blood viscosity and the domination of aggregation and deformation phenomena in forming the shape of this dependence were illustrated in the famous experiment by Chien [1, 3]. Blood plasma is a Newtonian fluid, whose viscosity does not depend on the shear rate. Plasma viscosity is determined by the presence of high molecular weight proteins like fibrinogen, immunoglobulins and lipoproteins [4]. Blood and plasma viscosity are subject to direct regulation by the organism. In particular one finds regulation achieved by changing the hematocrit and plasma viscosity [2].

Rheological studies of blood properties including both rotary measurements (flow curve) and oscillatory experiments (Dynamic Mechanical Analysis - DMA) are often complemented by experiments directly measuring red cells aggregability and deformability [1, 
5-7]. There are many techniques allowing achieving such results [5-8]. Similar information about erythrocytes properties can be achieved indirectly from the mathematical analysis of the flow curve with the use of rheological models $[1,9]$. In the literature one can find many models describing the flow of fluids. In the case of the flow of blood one should mention the model of Quemada $[1,10,11]$.

\section{Aim}

The aim of the present work was the analysis of the rheological properties of blood in a group of patients with different disorders on the basis of experimental results and available literature data.

\section{Hemorheology of chosen clinical cases}

The analysis of rheological properties of blood samples taken from patients with different disorders revealed not only different shape of obtained rheograms [12] but also statistically significant differences of rheological parameters values compared to the results in the reference group. The latter effect was observed in patients with cardiac disorders [9, 13], diabetes [13, 14], and neurological disorders [15-17].

Patients with acute ischemic stroke show elevated whole blood viscosity resulting from the increase in plasma viscosity (high fibrinogen concentration) and also from intensified erythrocytes aggregation and reduced red cells deformability. In patients after cerebral ischemic episode (a few months after the symptoms of ischemic stroke) no increase of blood viscosity is observed despite still elevated plasma viscosity, which probably results from some improvement of red cells elasticity. An inverse correlation between plasma viscosity and erythrocytes deformability in this group of patients has been found [16].

In a group of patients with clinically silent foci of cerebral ischemia no increase of whole blood or plasma viscosity have been found [18]. The improved red cells deformability observed in this group should probably be attributed to an autoregulatory mechanism. A negative feed-back between the IgM/fibrinogen indicator and erythrocytes aggregability has been found in this group which suggests an opposite role played by these two proteins in the aggregation phenomenon of red cells.

In patients with diabetes mellitus an elevated plasma viscosity is found which results in increased whole blood viscosity. In this group of patients intensified erythrocytes aggregability and reduced deformability have been found. Hemorheological factors probably play an important role in the formation of diabetic microangiopathy [19]. Analysis of the thermographic picture of upper and lower limbs perfusion and the hemorheological profile in diabetic patients revealed no statistically significant correlations. However, an increased value of whole blood viscosity was found in comparison to the control group as well as an increased tendency to pathological erythrocytes aggregation $[13,14]$.

Other examples are: patients with monoclonal paraproteinemia (Waldenstrom disease and multiple myelo$\mathrm{ma}$ ) - in these patients one observes increase of the blood viscosity as a result of elevated plasma viscosity which in turn results from excessive concentration of monoclonal proteins. Human organism regulates these rheological disorders by reduction of the synthesis of other immunoglobulins and erythropoietin (EPO). An inverse relation between plasma viscosity and EPO concentration has been found [20]. Plasma viscosity has been found as one of the factors influencing the transcription of the EPO gene, next to intracellular oxygen concentration and the HNF-4 factor (Haptocyte Nuclear Factor 4).

Changes of the values of hemorheological parameters were observed also in a group of patients with nephrotic syndrome in which a decrease of plasma proteins concentration occurs, mainly albumins. Albumins belong to low molecular weight proteins and their effect on plasma viscosity is connected with their high concentration in plasma. Regulatory response of the organism to a loss of albumins is an increased synthesis of fibrinogen and other macroglobulins. In nephrotic syndrome one also finds elevated concentration of lipids in plasma, which in turn is regulated by an inverse relation with the plasma viscosity [2].

Patients with true polycythemia show elevated blood viscosity as a result of high hematocrit value. These patients also demonstrate high plasma viscosity which results in a decrease of EPO concentration. Other harmful phenomena related to this pathology are reduced erythrocytes elasticity and an increased red cells aggregability.

In patients with arterial hypertension the increase of whole blood viscosity is a result of elevated hematocrit value and reduced red cells elasticity. In a group of patients with arterial hypertension after ischemic stroke a reduced activity of fibrinogen molecules in forming the inter-erythrocyte connections [21]. 


\section{Therapeutic methods influencing the hemorheological parameters}

The HELP system (heparin extracorporeal LDL precipitation), in which certain protein and lipid components of plasma are eliminated by means of specific filters, which allows for improvement of the hemorheological profile in the range of all parameters (blood viscosity, plasma viscosity, red cells aggregability and deformability) [22].

Classic plasmapheresis is a method in which a part of plasma is removed from the organism and then replaced with fusions of albumin suspensions or other blood substitutes. In this way a reduction of plasma and hence also whole blood viscosity is achieved (mainly in the range of small shear rates) as well as lowering of red cells aggregability [23]. Thefore, the hemorheological effect resembles the one observed in the case of using the HELP system.

Patients treated by intravenous infusions of gamma globulins. As a result of such therapy, plasma viscosity increases, but also the red cells elasticity improves which prevents increasing the whole blood viscosity. In the range of low shear rates the relative blood viscosity may even be reduced [24].

Hemodilution is a therapeutic method in which highly oncotic fluids are infused to the circulatory system, increasing in this way the blood volume and reducing the hematocrit value and blood viscosity. The use of hydroxyethyl starch (HES) additionally gives an effect of plasma viscosity reduction (due to low molecular weight of starch) as well as reduction of red cells aggregability; moreover the dilution effect last longest [25]. On the contrary, the use of low molecular dextrans does not provide such a positive influence on the hemorheological properties and even may have proaggregative function [25].

\section{Conclusions}

In this work we have presented the effect of the changes in hemoreological properties of blood in chosen clinical states or being a result of undertaken therapy. The analysis of changes of physico-chemical properties of blood performed in this work shows how important the hemorheological factor can be in applied therapy. Many hemorheological aspects of living organism functioning are not known yet. We believe that thanks to the new research methods we should learn better the autoregulatory mechanisms aiming at improvement of blood flow in order to be able to utilize them in the case when a living organism cannot do it by itself.

\section{Acknowledgements}

KBN nr N N402 482037

\section{Conflict of interest statement}

The authors declare that there is no conflict of interest in the authorship or publication of contribution.

\section{Funding sources}

There are no sources of funding to declare.

\section{References}

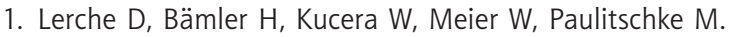
Flow properties of blood and hemorheological methods of quantification. In: Physical Characterization of Biological cells. Basic research and clinic relevance. Scütt W, Klinkmann H, Lamprecht I, Wilson T (eds.). Verlag Gesundheit GmbH Berlin, 1991; 189-214.

2. Reinhart WH. Molecular biology and self-regulatory mechanism of blood viscosity. A review. Biorheology. 2000;38:203-212.

3. Chien S, Jan KM. Ultrastructural basis of the mechanism of rouleaux formation. Microvas Res. 1973;5:155-166.

4. Lerche D, Koch B, Vlastos G. Flow behaviour of blood. Rheology. 1993;93:105-112.

5. Hardeman MR, Goedhart PT, Schut NH. Laser assisted Optical Rotational Cell Analyser (L.O.R.C.A). Red blood cell deformabitlyty; Elongation index versus cell transit time. Clin Hemorheol. 1994;14:619-630.

6. Hardeman MR, Goedhart PT, Dobbe JGG. Laser assisted Optical Rotational Cell Analyser (L.O.R.C.A). A new instrument for measurement of variuous structural hemorheological parameters. Clin. Hemorheol. 1994;14:605-618.

7. Sandhagen B. Assesment of blood rheology. Methodology and studies in healthy individuals, in patients with certain diseases and during liquid blood preservation. Acta Universitatis Upsaliensis, Uppsala; 1988.

8. Musielak M. Red blood cell-deformability measurenent: review of techniques. Clin Hemorheol Microcirc. 2009; 42:47-64.

9. Marcinkowska-Gapińska A, Gapiński J, Elikowski W, Jaroszyk F, Kubisz L. Comparison of three rheological models of shear flow behaviour studied on blood samples from post-infarction patients. Med Biol Eng Comp. 2007;45: 837-844.

10. Quemada D. A rheological model for studying the hematocrit dependence of red cell - red cell and red cell and red cell - protein interactions in blood. Biorheology. 1981;18:501-516.

11. Quemada D. Blood rheology and its implication in flow of blood. In: Arteries and arterial blood flow. Rodkiewicz CM (ed.). Springer Verlag, Vien-New York, 1983; 1-127.

12. Marcinkowska-Gapińska A, Jaroszyk F, Kubisz L. Blood rheograms made on patients after myocardial infarction. Sci. Proc. Riga Tech. Univ. Ser. 6. Transport and Engineering, 2002; 138-142.

13. Marcinkowska-Gapińska A, Kowal P. Blood fluidity and thermography in patients with diabetes mellitus and 
coronary artery disease in comparison to healthy subjects. Clin Hemorheol Microcirc. 2006;35:473-479.

14. Kowal P, Marcinkowska-Gapińska A. Badanie korelacji obrazu termograficznego z profilem hemoreologicznym u osób chorych na cukrzycę. Neuroskop. 2004;6:128-131 (in Polish).

15. Kowal P, Marcinkowska-Gapińska A. Comparison of the hemorheological parameters of blood in the groups of patients after cerebral stroke and myocardial infarction. Phys Med. 2004;20(Supplement):105-107.

16. Kowal P, Marcinkowska-Gapińska A. Hemorheological changes dependent on the time form the onset of ischemic stroke. J Neurol Sci. 2007;258(1-2):132-136.

17. Marcinkowska-Gapińska A, Kowal P. Comparative analysis of chosen hemorheological methods in a group of stroke patients. Clin Hemorheol Microcir. 2009;41:27-33.

18. Kowal P, Siemieniak I, Marcinkowska-Gapińska A. Próba oceny zmian hemoreologicznych w grupie pacjentów z niemymi klinicznie ogniskami niedokrwienia mózgu. Neuroskop. 2009;11:41-43 (in Polish).

19. Cho YI, Money MP, Cho DJ. Hemorheological disorders in diabetes mellitus. J Diabetes Sci Technol. 2008;2:11301238.

20. Singh A, Eckardt KV, Zimmermann A, Gotz KH, Hamann M, Ratcliffe PJ, Kurtz A, Reinhart WH. Increased plasma viscosity as a reason for inappropriate erythroprotein formation. J Clin Invest. 1993;91:251-256.

21. Kowal P. Arterial hypertension decreases fibrinogen molecules contribution to the inter-red cells connections in stroke patients. Clin Hemorheol Microcir. 1999;21: 321-324.
22. Seidel D. The HELP system: an efficient and safe method of plasmatherapy in the treatment of severe hybercholesterolemia. Ther Umsch. 1990;47:514-519.

23. Kowal P, Marcinkowska-Gapińska A, Kędzierski A, Siemienia I, Czekalski S, Kozubski W. Wpływ plazmaferezy klasycznej na profil hemoreologiczny u pacjentów z chorobami układu nerwowego. Badania pilotażowe. Neuroskop. 2009;11:34-36 (in Polish).

24. Kowal P, Zmyślony A. Hemorheological changes after intravenous gammaglobulin administration in patients with neurological disorders. Clin Hemorheol Microcir. 2008;40:229-234.

25. Marcinkowska-Gapińska A, Kowal P, Chałupka Z. The changes of low-shear rate hemorheological properties depending on the fluid used for transfusion. Clin Hemorheol Microcir. 2002;27:171-176.

Acceptance for editing: 2015-02-10 Acceptance for publication: 2015-03-30

Correspondence address:

Anna Marcinkowska-Gapińska Rheological Lab, Department of Neurology, Poznan University of Medical Sciences, Poland 49 Przybyszewskiego Str., 60-355 Poznan, Poland fax: +48 (61) 8691697 , email: margap@ump.edu.pl 